\title{
The kissing stents technique for a patient with chronic type B aortic dissection
}

\author{
Akihiro Yoshitake, MD, PhD, Takashi Hachiya, MD, PhD, Kanako Hayashi, MD, and \\ Hideyuki Shimizu, MD, PhD, Tokyo, Japan
}

From the Department of Cardiovascular Surgery, Keio University School of Medicine, Tokyo, Japan.

Disclosures: Authors have nothing to disclose with regard to commercial support.

Received for publication June 6, 2015; revisions received June 30, 2015; accepted for publication July 6, 2015; available ahead of print July 30, 2015.

Address for reprints: Akihiro Yoshitake, MD, PhD, Department of Cardiovascular Surgery, Keio University

School of Medicine, 35 Shinanomachi, Shinjuku, Tokyo, Japan (E-mail: akihiro197253@yahoo.co.jp).

J Thorac Cardiovasc Surg 2015;150:995-7

$0022-5223 / \$ 36.00$

Copyright (C) 2015 by The American Association for Thoracic Surgery

http://dx.doi.org/10.1016/j.jtcvs.2015.07.004

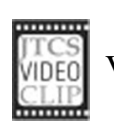

Video clip is available online.

Thoracic endovascular aortic repair has recently become widespread for patients with thoracic aneurysm. For patients with chronic type B aortic dissection, however, in whom the visceral arteries originate from a false lumen, blood flow from the false lumen is not always occluded, and there is concern that aneurysmal enlargement may occur in the false lumen through reentry. ${ }^{1}$ We describe here the "kissing stent" technique, in which 2 stent-graft main bodies are aligned in a parallel manner and the distal landing of one stent is placed into the true lumen with another stent graft placed into the false lumen.

\section{CLINICAL SUMMARY}

A 67-year-old man with an asymptomatic 72-mm saccular descending aortic aneurysm had a history of acute aortic dissection 12 years earlier and had undergone Y-grafting to the abdominal aortic aneurysm, proximal descending aortic replacement, and total arch replacement. He also had chronic obstructive pulmonary disease, coronary artery disease, and cerebral infarction and was therefore considered at high risk if undergoing open surgery. The aneurysm was located in the middle portion of the descending aorta. The distal descending aorta and thoracoabdominal aorta were double-barreled, and neither lumen was enlarged. The superior mesenteric and right renal arteries originated from the true lumen, and the celiac and left renal arteries originated from the false lumen.

An endovascular stent-graft operation was performed. The stent-graft main body (Gore TAG Thoracic Endoprosthesis; W.L. Gore and Associates, Flagstaff, Ariz) was delivered through the true lumen and placed into a prosthetic graft in the proximal descending aorta. The main body of another stent graft of the same size was inserted through the false lumen, with the upper end placed at almost the same level as the first stent graft. The grafts were deployed simultaneously at the same height. To secure the

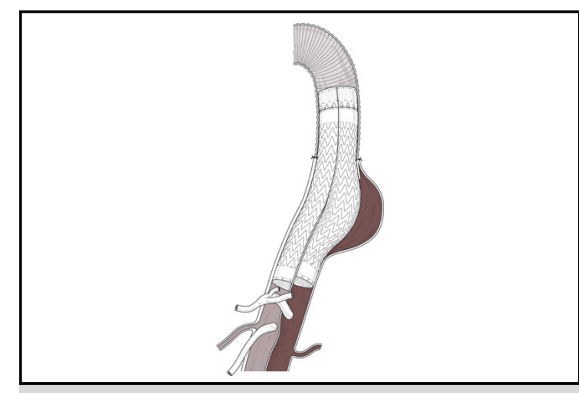

Stent grafts were inserted in parallel fashion, with distal landings in the true and false lumens.

\section{Central Message}

We performed a new thoracic endovascular aortic repair, named "kissing stent" technique, in a patient with chronic aortic dissection.

See Editorial Commentary page 997.

length of the proximal landing, the proximal extension cuff (Zenith Tx2 Thoracic Endoprosthesis; Cook Medical, Bloomington, Ind) was delivered into one side and the other cuff into the other side (Figure 1). Simultaneous touch-up

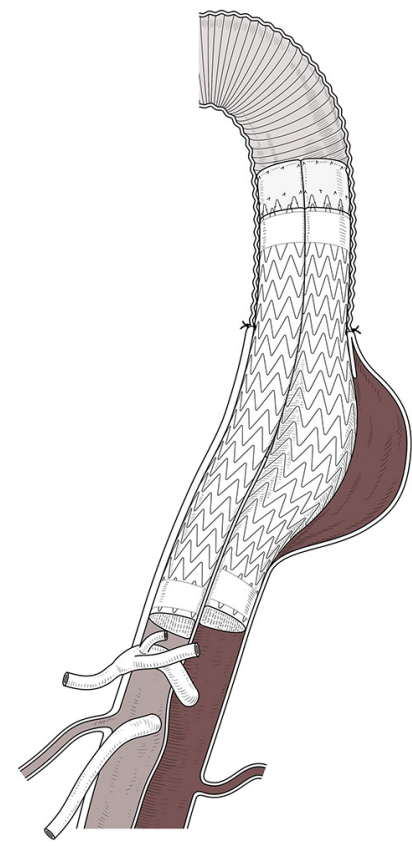

FIGURE 1. Postoperative diagram. Two stent-graft main bodies were inserted into the true and false lumens of the descending aorta in a parallel fashion. 


\section{pre}

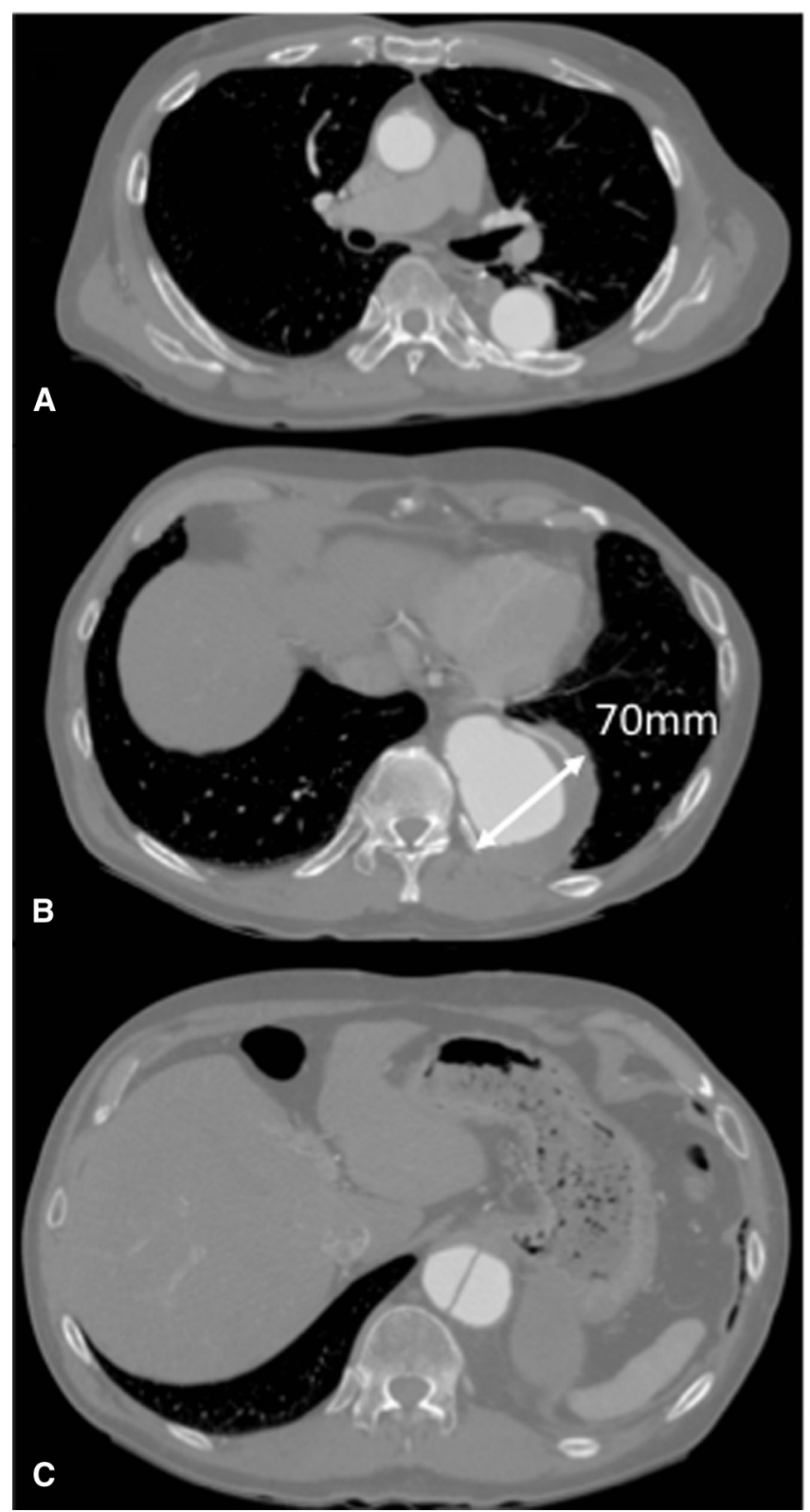

\section{post}

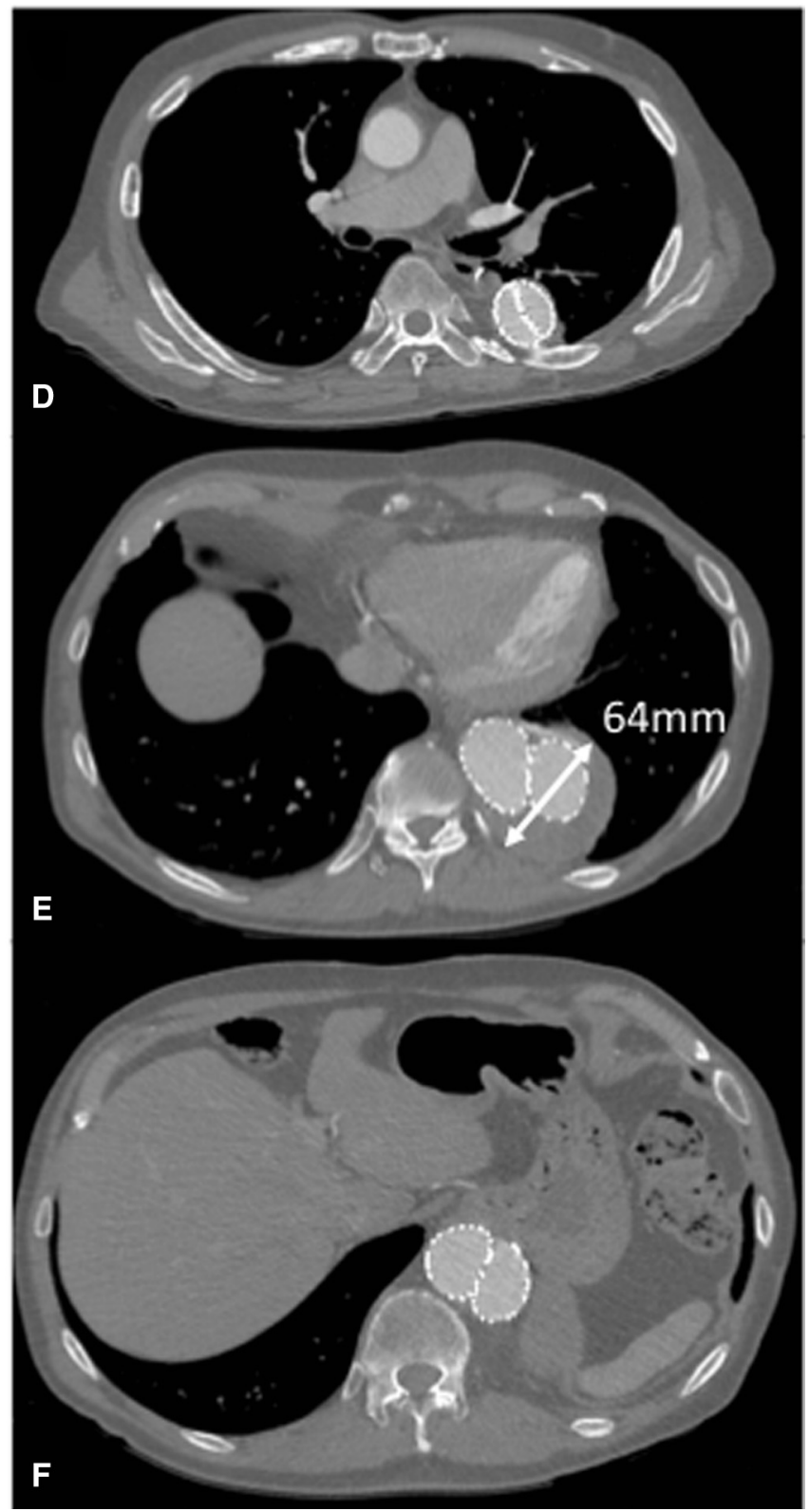

FIGURE 2. Computed tomographic axial image of the descending aorta preoperatively (A-C) and 6 months postoperatively (D-F). Neither stent-graft main body exhibits stenosis at the level of the proximal landing (D). The aneurysm shrank after the operation, and no endoleak was observed (E). One stent graft was placed in the true lumen, and the other was placed in the false lumen $(\mathrm{F})$.

was performed with a Coda Balloon Catheter (Cook Medical) in a kissing manner. Intraoperative angiography and postoperative computed tomographic angiography with delayed venous and arterial phases demonstrated good flow in both lumens, no endoleaks, and good stent-graft positioning (Video 1). The patient recovered fully without serious perioperative complications. Six months postoperatively, computed tomographic angiography showed aneurysm shrinkage and no endoleak (Figure 2). The patient's course remained uneventful at 11 months after surgery.

\section{DISCUSSION}

Endovascular treatment for acute type B aortic dissection has become widespread, with acceptable results. The International Registry of Acute Aortic Dissection reports that the 5 -year mortality among patients treated with thoracic endovascular aortic repair was superior to that among medically treated patients $(15.5 \%$ vs $29.0 \% ; P=.018){ }^{2}$

The use of thoracic endovascular aortic repair in patients with chronic type B aortic dissection, however, remains controversial. Relative to patients with acute aortic 
dissection, patients with chronic dissection display less consistent aortic remodeling (thoracic false-lumen thrombosis in 31\%-91\% among patients with chronic dissection vs $80 \%-90 \%$ among patients with acute dissection). ${ }^{3}$ Stentgraft coverage of the primary entry tear is often insufficient, leading to aneurysm formation in the distal aorta. In addition, some techniques have been shown to occlude the false lumen and promote thrombosis and false-lumen remodeling. ${ }^{4,5}$

The technique described here has some merit. The stent graft implanted into the false lumen completely blocked blood flow to the aneurysm and preserved blood flow to the celiac and renal arteries. In this case, neither the true nor the false lumen thrombosed, and neither lumen was perfused by the patent intercostal arteries, suggesting that this technique could be performed successfully. In our report, the false lumen served as the distal landing zone of one stent graft. After our patient's treatment for aortic dissection 12 years previously, the diameters of the distal descending aorta and thoracoabdominal aorta were nearly normal and did not change during follow-up. They thus appeared to have sufficient wall strength for stent-graft implantation.
This novel kissing stent technique was used effectively for a chronic aortic dissection aneurysm. It excluded the aneurysm completely and maintained blood flow to the visceral arteries. This technique may be an alternative for patients considered to be at high risk if undergoing open surgery.

\section{References}

1. Kang WC, Greenberg RK, Mastracci TM, Eagleton MJ, Hernandez AV, Pujara AC, et al. Endovascular repair of complicated chronic distal aortic dissections: intermediate outcomes and complications. J Thorac Cardiovasc Surg. 2011; 142:1074-83.

2. Fattori R, Montgomery D, Lovato L, Kische S, Di Eusanio M, Ince H, et al. Survival after endovascular therapy in patients with type B aortic dissection: a report from the International Registry of Acute Aortic Dissection (IRAD). JACC Cardiovasc Interv. 2013;6:876-82

3. Patterson BO, Cobb RJ, Karthikesalingam A, Holt PJ, Hinchliffe RJ, Loftus IM, et al. A systematic review of aortic remodeling after endovascular repair of type B aortic dissection: methods and outcomes. Ann Thorac Surg. 2014:97:588-95.

4. Idrees J, Roselli EE, Shafii S, Reside J, Lytle BW. Outcomes after false lumen embolization with covered stent devices in chronic dissection. J Vasc Surg. 2014;60:1507-13.

5. Kölbel T, Lohrenz C, Kieback A, Diener H, Debus ES, Larena-Avellaneda A Distal false lumen occlusion in aortic dissection with a homemade extra-large vascular plug: the candy-plug technique. $J$ Endovasc Ther. 2013;20:484-9.

\section{EDITORIAL COMMENTARY}

\section{Innovation is mandatory in chronic type $B$ aortic dissection}

\author{
Rune Haaverstad, MD, PhD, ${ }^{a}$ and Guttorm L. Jenssen, $\mathrm{MD}^{\mathrm{b}}$ \\ From the a Section of Cardiothoracic Surgery, Department of Heart Disease, Haukeland University Hospital, Ber- \\ gen, Norway; and the ${ }^{\mathrm{b}}$ Department of Radiology, Haukeland University Hospital, Bergen, Norway. \\ Disclosures: Authors have nothing to disclose with regard to commercial support. \\ Received for publication July 23, 2015; accepted for publication July 24, 2015; available ahead of print Aug 15, \\ 2015. \\ Address for reprints: Rune Haaverstad, MD, PhD, Section of Cardiothoracic Surgery, Department of Heart Dis- \\ ease, Bergen University Hospital, Bergen, Norway (E-mail: rhaavers@online.no). \\ J Thorac Cardiovasc Surg 2015;150:997-9 \\ $0022-5223 / \$ 36.00$ \\ Copyright (C) 2015 by The American Association for Thoracic Surgery \\ http://dx.doi.org/10.1016/j.jtcvs.2015.07.072
}

Chronic type B aortic dissection (cTBAD), either primary or secondary after open surgery for acute type A aortic dissection, remains a threat for the patient and a major medical challenge. The cTBADs are heterogeneous with regard to patient-related risk factors, interval since onset, morphology, false-lumen status, site, and numbers of entries and reentries, as well as varying origins of the spinal and visceral arteries. In the long run, rupture of a false lumen aneurysm causes most of the dissection-related mortality. Traditionally, cTBAD has been treated with open surgery, but because this carries a high risk in patients

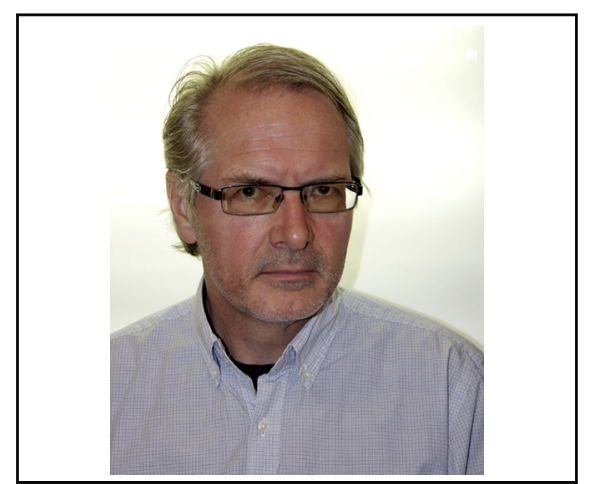

Rune Haaverstad, MD, PhD

Central Message

An innovative endovascular "kissing stents" technique may avoid rupture and ensure distal perfusion in chronic type B aortic dissection.

See Article page 995. 